\title{
RENDIMENTO E NODULAÇÃO DE SOJA EM DIFERENTES ROTAÇÕES DE ESPÉCIES ANUAIS DE INVERNO SOB PLANTIO DIRETO'1
}

\author{
RENATO SERENA FONTANELI ${ }^{2}$, HENRIQUE PEREIRA DOS SANTOS ${ }^{3}$, MARCIO VOSS $^{4}$ e IVO AMBROSI $^{5}$
}

\begin{abstract}
RESUMO - O presente estudo teve como objetivo comparar diferentes culturas antecessoras com o rendimento de grãos e com a nodulação de soja, no campo experimental da Faculdade de Agronomia e Medicina Veterinária, em Passo Fundo, RS. Os tratamentos consistiram em quatro sucessões com forrageiras anuais de inverno (aveia-branca, aveia-preta pastejada, aveia-preta + ervilhaca pastejada, e trigo), sendo a soja semeada após. As culturas, tanto no inverno como no verão, foram estabelecidas sob sistema plantio direto. O delineamento experimental foi em blocos ao acaso, com três repetições, e parcelas totalizando $500 \mathrm{~m}^{2}$. Os resultados indicaram que na média dos anos não houve diferenças significativas entre o tipo de cultura antecessora e o rendimento de grãos de soja. Após cinco anos de sistema plantio direto, observou-se nodulação abundante em soja, em todos os sistemas de produção. A soja cultivada após aveia-branca, após aveia-preta pastejada, após aveia-preta + ervilhaca pastejada ou após trigo, pode ser incluída, sem prejuízo, nesses diferentes sistemas estudados.
\end{abstract}

Termos para indexação: rotação de culturas, sucessão de culturas, aveia-branca, aveia-preta, ervilhaca, trigo.

\section{SOYBEAN YIELD AND NODULATION IN DIFFERENT ANNUAL WINTER CROPS UNDER NO-TILLAGE}

\begin{abstract}
The different preceding crops were compared in relation to soybean yield and nodulation during four years at the Faculdade de Agronomia e Medicina Veterinária, in Passo Fundo, State of Rio Grande do Sul, Brazil. Four production systems with annual winter pastures were tested, in which soybean was sown after different winter crops (white oats, grazed black oats, grazed black oats + grazed common vetch, and wheat). Both in winter and summer the crops were grown under notillage. An experimental design of blocks at random, with three replications and plots with $500 \mathrm{~m}^{2}$, was used. No significant differences between type of preceding crop and soybean yield were found in the mean of years. After five years of no-tillage, an abundant nodulation in soybean was observed in all production systems. Soybean grown after white oats, grazed black oats, grazed black oats + grazed common vetch, and wheat may be included, without any loss, in the different systems studied.
\end{abstract}

Index terms: crop rotation, crop succession, white oats, black oats, common vetch, wheat.

\section{INTRODUÇÃO}

A monocultura, ou mesmo o sistema de sucessão trigo-soja continuamente, com o passar dos anos, provoca a degradação física, química e biológica e,

\footnotetext{
${ }^{1}$ Aceito para publicação em 24 de março de 1999.

Trabalho realizado com recursos parciais da FAPERGS.

${ }^{2}$ Eng. Agrôn., M.Sc., Embrapa-Centro Nacional de Pesquisa de Trigo (CNPT), Caixa Postal 451, CEP 99001-970 Passo Fundo, RS

${ }^{3}$ Eng. Agrôn., Dr., Embrapa-CNPT. Bolsista do CNPq. E-mail: hpsantos@cnpt.embrapa.br

${ }^{4}$ Eng. Agrôn., Dr., Embrapa-CNPT.

${ }^{5}$ Economista, M.Sc., Embrapa-CNPT.
}

conseqüentemente, a redução da produtividade das culturas (Reunião..., 1995). Também proporciona condições mais favoráveis ao desenvolvimento de doenças, de pragas e de plantas daninhas.

A rotação de culturas merece especial atenção no manejo e controle das doenças de soja, pois a decomposição dos restos culturais elimina o substrato nutritivo dos patógenos que permanecem viáveis nesses restos (Reunião..., 1995). Sugere-se realizar a rotação com culturas não hospedeiras dos mesmos patógenos, como milho ou sorgo.

A rotação de culturas, como prática corrente na produção agrícola, tem recebido, através do tempo, reconhecimento acentuado, do ponto de vista técnico, como um dos meios indispensáveis ao bom de- 
senvolvimento de uma agricultura estável. Diversos estudos têm demonstrado os efeitos benéficos da rotação de culturas, tanto sobre as condições de solo quanto sobre a produção das culturas subseqüentes (Reis et al., 1983; Gaudêncio et al., 1986; Santos et al., 1993).

O sistema plantio direto, além de reduzir as perdas de solo, tanto no inverno como no verão, possibilita a semeadura de soja em sua época recomendada (Barker \& Wünsche, 1977). Por outro lado, a cobertura vegetal de solo, no sistema plantio direto, pode causar efeitos alelopáticos sobre o desenvolvimento de plantas na evolução de doenças, que proliferam em tecidos mortos deixados na superfície do solo, causando a diminuição do rendimento de grãos das culturas em sucessão (Santos \& Reis, 1991).

Em sistema plantio direto, foi constatado o favorecimento à nodulação das raízes de soja, em comparação com plantio em preparo convencional de solo, em experimentos em que não houve pastejo, em Londrina e em Carambeí, no Paraná (Voss \& Sidiras, 1985).

Nos sistemas de rotação de culturas desenvolvidos no sul do Brasil referentes a cereais de inverno, onde a soja foi semeada em sistemas de monocultura, com um verão sem soja, com um verão sem e dois com soja, com um verão sem e três com soja, sob sistema plantio direto, não foram observados efeitos relevantes sobre as doenças dessa leguminosa ao longo de dez anos (Santos \& Wobeto, 1994; Santos et al., 1994a). Nesse período, não houve intensidade relativamente alta das doenças que hoje estão incidindo sobre a cultura de soja (Costamilan \& Lhamby, 1994; Reunião..., 1995).

O estudo de várias combinações de rotação ou sucessão de culturas para soja, em Londrina, PR, revelou que dois verões de rotação com milho elevaram o rendimento de grãos dessa leguminosa nas duas safras seguintes, na quase totalidade dos arranjos, em relação à monocultura (Gaudêncio et al., 1986). No trabalho desenvolvido na região de Cruz Alta, RS, Ruedell (1995) observou que a soja em rotação de culturas produziu mais do que a monocultura, tanto no plantio direto como no preparo convencional de solo.
O presente trabalho teve por objetivo comparar diferentes culturas e forrageiras anuais de inverno sobre o rendimento de grãos e sobre a nodulação de soja, em sistema plantio direto.

\section{MATERIAL E MÉTODOS}

O ensaio foi conduzido no campo experimental, da Faculdade de Agronomia e Medicina Veterinária da Universidade de Passo Fundo (UPF), município de Passo Fundo, RS, de 1990 a 1995, em solo classificado como Latossolo Vermelho-Escuro distrófico (Brasil, 1973).

Os tratamentos consistiram em quatro seqüências com diferentes culturas e espécies forrageiras anuais de inverno (aveia-branca, aveia-preta pastejada, aveia-preta + ervilhaca pastejada e trigo), e soja semeada em sucessão. Em 1990, havia trevo-vesiculoso no lugar de ervilhaca (Tabela 1). As culturas, tanto no inverno como no verão, foram estabelecidas sob sistema plantio direto. As cultivares de soja utilizadas foram Bragg e BR-4, em 1990, BR-4, em 1991 e em 1992, e BR-16, de 1993 a 1995.

Em abril de 1990, antes da semeadura das culturas de inverno foram coletadas amostras de solo $(0-20 \mathrm{~cm})$, cujos valores médios indicavam: $\mathrm{pH}=5,4$, $\mathrm{Al}$ trocável $=2,5 \mathrm{mmol}_{\mathrm{c}} \mathrm{dm}^{-3}, \mathrm{Ca}+\mathrm{Mg}$ trocáveis $=89,8 \mathrm{mmol}_{\mathrm{c}} \mathrm{dm}^{-3}$, matéria orgânica $=32 \mathrm{~g} \mathrm{~kg}^{-1}$, $\mathrm{P}$ extraível $=11,5 \mathrm{mg} \mathrm{kg}^{-1} \mathrm{e} \mathrm{K}$ trocável $=138 \mathrm{mg} \mathrm{kg}^{-1}$.

A adubação de manutenção foi realizada de acordo com a recomendação para cada cultura e baseada nos resultados da análise de solo. As amostras de solo foram coletadas a cada três anos, após as culturas de verão.

A época de semeadura e o controle de plantas daninhas obedeceram à recomendação para a cultura de soja, e a colheita foi realizada com automotriz especial para parcelas. As parcelas mediam, aproximadamente, $500 \mathrm{~m}^{2}$.O rendimento de grãos foi determinado a partir da colheita de $1 / 3$ das parcelas, ajustando-se para umidade de $13 \%$.

O pastejo da aveia-preta e de ervilhaca foi realizado por bovinos mistos (corte e leite) quando a aveia-preta atingiu estatura de, aproximadamente, $30 \mathrm{~cm}$, deixandose uma altura de resteva de 7 a $10 \mathrm{~cm}$. Os bovinos (de 15 a 18 animais) foram colocados nas parcelas quando o solo não apresentava excesso de umidade e consumiam a forragem disponível geralmente no primeiro dia. Realizaramse dois a três pastejos por ano, geralmente em junho, em julho e em agosto. Nessa ocasião, foi avaliada a matéria verde, antes e depois do pastejo, e, posteriormente, a matéria seca. Após o último pastejo, permitia-se um rebrote durante 30 a 40 dias, quando acumulava-se uma cobertura verde de $1,5 \mathrm{t}$ a 2,0 $\mathrm{t}$ de matéria seca por hectare, desse- 
cando-se, então, a vegetação para a semeadura das culturas de verão.

A inoculação de soja com Bradyrhizobium sp. foi realizada com inoculante turfoso comercial. Na safra 1994/1995, a nodulação de soja foi avaliada em um metro linear por parcela, em escavação centralizada na linha de semeadura, com $15 \mathrm{~cm}$ de profundidade e $15 \mathrm{~cm}$ de largura. Os nódulos foram lavados, destacados, secados até peso constante e pesados.

Em maio de 1996, após as culturas de verão, foram coletadas amostras de solo compostas (três subamostras por parcela) nas profundidades $0-5 \mathrm{~cm}, 5-10 \mathrm{~cm}$, $10-20 \mathrm{~cm}$ e $20-30 \mathrm{~cm}$. As análises (pH em água, P extraível, $\mathrm{K}$ trocável, matéria orgânica, $\mathrm{Al}$ trocável e $\mathrm{Ca}+\mathrm{Mg}$ trocáveis) seguiram a metodologia descrita por Tedesco et al. (1985).

O delineamento experimental foi em blocos ao acaso, com três repetições. Foi efetuada a análise de variância do rendimento de grãos (dentro de cada ano e na média conjunta dos anos), de 1992 a 1995. Considerou-se a comparação do tratamento (diferentes restevas de inverno) como fixo, e o efeito do ano, como aleatório. As médias foram comparadas entre si pela aplicação do teste de Duncan, a $5 \%$ de probabilidade.

\section{RESULTADOS E DISCUSSÃO}

Na avaliação de maio de 1996, não houve diferenças significativas entre as médias dos diferentes sistemas de produção estudados, nos valores de $\mathrm{pH}$, de $\mathrm{Al}$ trocável e de $\mathrm{Ca}+\mathrm{Mg}$ trocáveis do solo. Por ocasião dessa avaliação, o sistema III $\left(33,7 \mathrm{~g} \mathrm{~kg}^{-1}\right)$ apresentou valor de matéria orgânica do solo maior, em relação ao sistema II $\left(31,8 \mathrm{~g} \mathrm{~kg}^{-1}\right)$, na camada 0-5 cm. Observou-se valor de P extraível do solo, na camada $0-5 \mathrm{~cm}$ maior, no sistema IV $\left(28,6 \mathrm{mg} \mathrm{kg}^{-1}\right)$ do que nos sistemas II $\left(18,9 \mathrm{mg} \mathrm{kg}^{-1}\right)$ e III $\left(20,5 \mathrm{mg} \mathrm{kg}^{-1}\right)$. O teor de $\mathrm{K}$ trocável, nas camadas de 0-5 cm a 20-30 cm, foi mais elevado no sistema IV do que nos sistemas I, II e III. Isso pode ser reflexo da aveia-preta e aveia-preta + ervilhaca que foram pastejadas de duas a três vezes, durante esse período de estudo, portanto extraíram e removeram mais esses elementos do que as culturas do sistema IV, usadas somente para produção de grãos. Além disso, parte desses elementos deve ter sido retornado ao solo através dos resíduos vegetais.

O pH do solo, na avaliação de maio de 1996 e em todos os sistemas, esteve mais baixo na camada $0-5$ $\mathrm{cm}(5,1)$ do que nas camadas $5-10 \mathrm{~cm}(5,3)$ e $10-20 \mathrm{~cm}(5,2)$ (Tabela 2). Além disso, diminuiu gradativamente da camada $5-10 \mathrm{~cm}(5,3)$ para a camada 20-30 cm $(4,9)$. Por sua vez, o Al trocável aumentou gradativamente da camada $5-10 \mathrm{~cm}$ $\left(7,6 \mathrm{mmol}_{\mathrm{c}} \mathrm{dm}^{-3}\right)$ para a camada $20-30 \mathrm{~cm}$ $\left(23,3 \mathrm{mmol}_{\mathrm{c}} \mathrm{dm}^{-3}\right)$. O valor médio de $\mathrm{Ca}+\mathrm{Mg}$ trocáveis

TABELA 1. Sistemas de rotação de culturas com espécies anuais de inverno para grãos e forragens, no período de 1990 a 1995. Passo Fundo, RS, 1996².

\begin{tabular}{|c|c|c|c|c|c|c|}
\hline $\begin{array}{l}\text { Sistema } \\
\text { de rotação }\end{array}$ & 1990 & 1991 & 1992 & 1993 & 1994 & 1995 \\
\hline \multirow[t]{3}{*}{ I } & $\mathrm{T} / \mathrm{S}$ & $\mathrm{Ap} / \mathrm{S}$ & $\mathrm{Ap} / \mathrm{S}$ & $\mathrm{T} / \mathrm{S}$ & $\mathrm{Ap} / \mathrm{S}$ & $\mathrm{Ap} / \mathrm{S}$ \\
\hline & $\mathrm{Ap} / \mathrm{S}$ & $\mathrm{Ap} / \mathrm{S}$ & $\mathrm{T} / \mathrm{S}$ & $\mathrm{Ap} / \mathrm{S}$ & $\mathrm{Ap} / \mathrm{S}$ & $\mathrm{T} / \mathrm{S}$ \\
\hline & $\mathrm{Ap} / \mathrm{S}$ & $\mathrm{T} / \mathrm{S}$ & $\mathrm{Ap} / \mathrm{S}$ & $\mathrm{Ap} / \mathrm{S}$ & $\mathrm{T} / \mathrm{S}$ & $\mathrm{Ap} / \mathrm{S}$ \\
\hline \multirow[t]{2}{*}{ II } & $\mathrm{T} / \mathrm{S}$ & $\mathrm{Ap}+\mathrm{E} / \mathrm{M}$ & $\mathrm{T} / \mathrm{S}$ & $\mathrm{Ap}+\mathrm{E} / \mathrm{M}$ & $\mathrm{T} / \mathrm{S}$ & $\mathrm{Ap}+\mathrm{E} / \mathrm{M}$ \\
\hline & $\mathrm{Ap}+\mathrm{Tv} / \mathrm{M}$ & $\mathrm{T} / \mathrm{S}$ & $\mathrm{Ap}+\mathrm{E} / \mathrm{M}$ & $\mathrm{T} / \mathrm{S}$ & $\mathrm{Ap}+\mathrm{E} / \mathrm{M}$ & $\mathrm{T} / \mathrm{S}$ \\
\hline \multirow[t]{3}{*}{ III } & $\mathrm{T} / \mathrm{S}$ & $A p+E / S$ & $\mathrm{Ap}+\mathrm{E} / \mathrm{M}$ & $\mathrm{T} / \mathrm{S}$ & $A p+E / S$ & $\mathrm{Ap}+\mathrm{E} / \mathrm{M}$ \\
\hline & $\mathrm{Ap}+\mathrm{Tv} / \mathrm{S}$ & $\mathrm{Ap}+\mathrm{E} / \mathrm{M}$ & $\mathrm{T} / \mathrm{S}$ & $A p+E / S$ & $\mathrm{Ap}+\mathrm{E} / \mathrm{M}$ & $\mathrm{T} / \mathrm{S}$ \\
\hline & $\mathrm{Ap}+\mathrm{Tv} / \mathrm{M}$ & $\mathrm{T} / \mathrm{S}$ & $\mathrm{Ap}+\mathrm{E} / \mathrm{S}$ & $\mathrm{Ap}+\mathrm{E} / \mathrm{M}$ & $\mathrm{T} / \mathrm{S}$ & $\mathrm{Ap}+\mathrm{E} / \mathrm{S}$ \\
\hline \multirow[t]{3}{*}{ IV } & $\mathrm{T} / \mathrm{S}$ & $\mathrm{Ab} / \mathrm{S}$ & $\mathrm{Ab} / \mathrm{S}$ & $\mathrm{T} / \mathrm{S}$ & $\mathrm{Ab} / \mathrm{S}$ & $\mathrm{Ab} / \mathrm{S}$ \\
\hline & $\mathrm{Ab} / \mathrm{S}$ & $\mathrm{Ab} / \mathrm{S}$ & $\mathrm{T} / \mathrm{S}$ & $\mathrm{Ab} / \mathrm{S}$ & $\mathrm{Ab} / \mathrm{S}$ & $\mathrm{T} / \mathrm{S}$ \\
\hline & $\mathrm{Ab} / \mathrm{S}$ & $\mathrm{T} / \mathrm{S}$ & $\mathrm{Ab} / \mathrm{S}$ & $\mathrm{Ab} / \mathrm{S}$ & $\mathrm{T} / \mathrm{S}$ & $\mathrm{Ab} / \mathrm{S}$ \\
\hline
\end{tabular}

${ }^{1} \mathrm{Ab}$ : aveia-branca; Ap: aveia-preta; E: ervilhaca; M: milho, S: soja; T: trigo; Tv: trevo vesiculoso. 
do solo mostrado na camada $0-5 \mathrm{~cm}$ $\left(60,4 \mathrm{mmol}_{\mathrm{c}} \mathrm{dm}^{-3}\right)$ a $10-20 \mathrm{~cm}\left(61,3 \mathrm{mmol}_{\mathrm{c}} \mathrm{dm}^{-3}\right)$ é considerado alto para o crescimento e desenvolvimento das culturas presentes na região (Sociedade Brasileira de Ciência do Solo, 1995). Os valores de $\mathrm{Ca}+\mathrm{Mg}$ trocáveis do solo também estiveram relacionados com os valores de $\mathrm{pH}$.

Quanto aos valores de matéria orgânica, em todas as seqüências, houve redução progressiva da camada superficial $\left(34,0 \mathrm{~g} \mathrm{~kg}^{-1}\right)$ na camada mais profunda (23,8 $\left.\mathrm{g} \mathrm{kg}^{-1}\right)$ (Tabela 2). A manutenção do teor de matéria orgânica em valores mais elevados apenas na camada superficial do solo decorre do acúmulo de resíduos vegetais sobre a superfície do solo sob sistema plantio direto, em função da ausência de incorporação física destes através do revolvimento do solo, praticada na semeadura com preparo convencional de solo, a qual diminui a taxa de mineralização (Muzilli, 1983). O teor de P extraível (23 $\left.\mathrm{mg} \mathrm{kg}^{-1}\right)$ e de $\mathrm{K}$ trocável do solo $\left(152 \mathrm{mg} \mathrm{kg}^{-1}\right)$ na camada superficial $(0-5 \mathrm{~cm})$, em todas as rotações de inverno, foi superior ao valor considerado crítico, nesse tipo de solo (12,0 mg kg-1 e $120 \mathrm{mg} \mathrm{kg}^{-1}$, respectivamente), com relação a crescimento e desenvolvimento das culturas presentes na região (Sociedade Brasileira de Ciência do Solo, 1995). Em todas as rotações, o teor de P extraível na camada $0-5 \mathrm{~cm}\left(23 \mathrm{mg} \mathrm{kg}^{-1}\right)$ foi 4,3 vezes maior do que os teores registrados na camada $10-20 \mathrm{~cm}\left(5,3 \mathrm{mg} \mathrm{kg}^{-1}\right)$. Por outro lado, o teor de $\mathrm{K}$ trocável, na camada $0-5 \mathrm{~cm}\left(152 \mathrm{mg} \mathrm{kg}^{-1}\right)$ foi 3,1 vezes maior que a concentração verificada na camada $10-20 \mathrm{~cm}\left(49 \mathrm{mg} \mathrm{kg}^{-1}\right)$.
Como se tratava de sistema plantio direto, era de se esperar acúmulo de $\mathrm{P}$ extraível e de $\mathrm{K}$ trocável próximo da superfície decorrente das aplicações anuais de fertilizantes fosfatado e potássico.

O rendimento de grãos de soja foi analisado a partir de 1992, ano em que se completou o primeiro ciclo de sucessão ou de rotação de culturas. Os resultados do rendimento de grãos de soja podem ser observados na Tabela 3. Essa variável foi significativamente influenciada pelo fator ano. Isso indica que essa característica foi afetada pelas variações climáticas ocorridas entre os anos. Resultados semelhantes foram obtidos por Santos et al. (1994b).

Com relação ao ano de 1992, houve diferenças significativas quanto ao rendimento de grãos de soja, em razão do tipo de cultura antecessora, o que indica que os sistemas de rotação de culturas envolvendo aveia-branca, aveia-preta pastejada, aveia-preta + ervilhaca pastejada e trigo, utilizados como resteva de inverno, nesse ano, apresentaram efeitos diferenciados sobre a soja, nessa variável. Entretanto, nos demais anos (1993 a 1995) e na média conjunta dos anos, isso não foi verdadeiro, ou seja, as médias não diferiram significativamente entre si quanto ao rendimento de grãos. Resultados similares foram obtidos por Ruedell (1995), durante dez anos, com a soja sendo antecedida por aveia-preta, por aveia-preta + ervilhaca e por trigo, sob sistema plantio direto.

No ano de 1992, a soja cultivada após aveia-preta + ervilhaca, no sistema III, e após trigo, no sistema II, mostrou rendimento de grãos mais elevado. Entretanto, este último sistema não foi diferente,

TABELA 2. Valores de pH, de alumínio, de cálcio + magnésio trocáveis, de matéria orgânica, de fósforo e de potássio, em diferentes profundidades de solo, Passo Fundo, RS, 1996.

\begin{tabular}{lcccr}
\hline Variável & \multicolumn{4}{c}{ Profundidade $(\mathrm{cm})$} \\
\cline { 2 - 4 } & $0-5$ & $5-10$ & $10-20$ & $20-30$ \\
\hline pH em água 1:1 & 5,1 & 5,3 & 5,2 & 4,9 \\
Al trocável $\left(\mathrm{mmol}_{\mathrm{c}} \mathrm{dm}^{-3}\right)$ & 7,9 & 7,6 & 11,9 & 23,3 \\
$\mathrm{Ca}+\mathrm{Mg}$ trocáveis $\left(\mathrm{mmol}_{\mathrm{c}} \mathrm{dm}^{-3}\right)$ & 60,4 & 61,3 & 52,4 & 33,1 \\
Matéria orgânica $\left(\mathrm{g} \mathrm{kg}^{-1}\right)$ & 34,0 & 27,7 & 25,7 & 23,8 \\
P extraível $\left(\mathrm{mg} \mathrm{kg}^{-1}\right)$ & 23,0 & 10,4 & 5,3 & 2,2 \\
K trocável $\left(\mathrm{mg} \mathrm{kg}^{-1}\right)$ & 152,0 & 78,0 & 49,0 & 30,0 \\
\hline
\end{tabular}


estatisticamente, quando comparado com a soja cultivada após trigo, no sistema III, após trigo, no sistema I, após aveia-preta, no sistema I, e após aveia-branca, no sistema IV. Deve ser levado em consideração que, nesse ano, os maiores rendimentos de soja, em valores absolutos, tiveram a ervilhaca antes de trigo/soja.

Em 1995, a cultura de soja produziu, em média, $3.245 \mathrm{~kg} / \mathrm{ha}$ (Tabela 3). Esse valor foi o mais elevado, em comparação aos demais anos estudados. Pelo que se observou, nesse ano, a precipitação pluvial (765 mm) situou-se acima da exigida por essa leguminosa (aproximadamente $700 \mathrm{~mm}$ ). Nesse caso, a precipitação pluvial foi bem distribuída, principalmente no estádio de florescimento pleno de soja.

$\mathrm{Na}$ interação ano x tipo de sucessão, o rendimento de grãos de soja diferiu significativamente. Esse resultado está de acordo com o obtido por Santos et al. (1989a, 1989b).

A ocorrência de doenças da soja, que se tem acentuado nos últimos anos, como a podridão-parda-dahaste, causada por Phialophora gregata, e o cancro-da-haste, causado por Diaporthe phaseolorum f. sp. meridionalis (Reunião..., 1993; Costamilan \& Lhamby, 1994), fez com que a cultivar BR-4, utilizada de 1990 a 1992, que era suscetível à podridão-parda-da-haste, fosse substituída pela BR-16, resistente a essas moléstias.

Deve-se notar que nos sistemas I, III e IV havia dupla ou tripla monocultura de soja. Contudo, nesses seis anos, pela observação de campo, foi registrada incidência relativamente baixa de doenças da parte aérea, sem afetar o rendimento de grãos dessa leguminosa. No trabalho conduzido em Londrina por Gaudêncio et al. (1986), durante três anos, a soja cultivada após milho por dois verões $(2.094 \mathrm{~kg} / \mathrm{ha})$ rendeu mais do que a soja cultivada após monocultura $(1.892 \mathrm{~kg} / \mathrm{ha})$ e após milho por um verão $(1.892 \mathrm{~kg} / \mathrm{ha})$. Isso, por sua vez, foi independente da cultura antecessora de inverno. $\mathrm{O}$ trabalho realizado em Cruz Alta por Ruedell (1995), durante dez anos, revelou que a soja cultivada em sistemas de rotação de culturas de verão $(3.196 \mathrm{~kg} / \mathrm{ha})$ apresentou maior rendimento que a soja cultivada em monocultura $(2.821 \mathrm{~kg} / \mathrm{ha})$. No trabalho conduzido em Maracaju por Broch et al. (1997), a soja cultivada após pasta-

TABELA 3. Rendimento de grãos e peso de matéria seca de nódulos de soja cultivada, em sistemas de rotação de culturas, após forrageiras anuais de inverno. Passo Fundo, RS, 1996¹.

\begin{tabular}{|c|c|c|c|c|c|c|c|}
\hline \multirow[t]{2}{*}{$\begin{array}{l}\text { Sistema de } \\
\text { rotação }\end{array}$} & \multirow{2}{*}{$\begin{array}{c}\text { Culturas } \\
\text { anteriores } \\
\text { à soja }^{2}\end{array}$} & \multicolumn{4}{|c|}{$\begin{array}{l}\text { Rendimento } \\
(\mathrm{kg} / \mathrm{ha})\end{array}$} & \multirow[t]{2}{*}{ Média } & \multirow{2}{*}{$\begin{array}{c}\begin{array}{c}\text { Peso de } \\
\text { nódulo } \\
\text { (mg/planta) }\end{array} \\
1994 / 1995\end{array}$} \\
\hline & & 1992 & 1993 & 1994 & 1995 & & \\
\hline I & $\begin{array}{l}\text { T, Ap, Ap } \\
\text { Ap, Ap, T } \\
\text { Ap, T, Ap }\end{array}$ & $\begin{array}{l}2.336 \mathrm{bc} \\
2.068 \mathrm{bc} \\
1.845 \mathrm{c}\end{array}$ & $\begin{array}{l}2.667 \\
2.567 \\
2.675\end{array}$ & $\begin{array}{l}2.820 \\
2.668 \\
2.775\end{array}$ & $\begin{array}{l}2.860 \\
3.214 \\
3.220\end{array}$ & $\begin{array}{l}2.671 \\
2.629 \\
2.628\end{array}$ & $\begin{array}{l}425 \\
372 \\
410\end{array}$ \\
\hline II & $\mathrm{T}, \mathrm{Ap}+\mathrm{E} / \mathrm{M}$ & $2.568 \mathrm{ab}$ & 2.767 & 2.747 & 3.402 & 2.871 & 422 \\
\hline III & $\begin{array}{l}T, A p+E / M, A p+E \\
A p+E, T\end{array}$ & $\begin{array}{l}2.446 \mathrm{~b} \\
3.022 \mathrm{a}\end{array}$ & $\begin{array}{l}2.692 \\
2.833\end{array}$ & $\begin{array}{l}2.845 \\
2.861\end{array}$ & $\begin{array}{l}3.158 \\
3.278\end{array}$ & $\begin{array}{l}2.785 \\
2.999\end{array}$ & $\begin{array}{l}291 \\
348\end{array}$ \\
\hline IV & $\begin{array}{l}T, A b, A b \\
A b, A b, T \\
A b, T, A b\end{array}$ & $\begin{array}{l}1.857 \mathrm{c} \\
1.916 \mathrm{c} \\
2.092 \mathrm{bc}\end{array}$ & $\begin{array}{l}2.542 \\
2.575 \\
2.758\end{array}$ & $\begin{array}{l}2.606 \\
2.889 \\
2.744\end{array}$ & $\begin{array}{l}3.299 \\
3.426 \\
3.348 \\
\end{array}$ & $\begin{array}{l}2.576 \\
2.701 \\
2.736\end{array}$ & $\begin{array}{l}295 \\
381 \\
304 \\
\end{array}$ \\
\hline $\begin{array}{l}\text { Média } \\
\text { C.V. }(\%) \\
\text { F tratamentos }\end{array}$ & & $\begin{array}{r}2.239 \\
13 \\
5 * *\end{array}$ & $\begin{array}{r}2.675 \\
9 \\
1^{\mathrm{ns}}\end{array}$ & $\begin{array}{r}2.773 \\
10 \\
1^{\mathrm{ns}}\end{array}$ & $\begin{array}{r}3.245 \\
6 \\
2^{\text {ns }}\end{array}$ & $\begin{array}{c}2.732 \\
- \\
2^{\mathrm{ns}}\end{array}$ & $\begin{array}{c}361 \\
33 \\
0,6^{\mathrm{ns}}\end{array}$ \\
\hline
\end{tabular}

${ }^{1}$ Médias seguidas da mesma letra, na coluna, não apresentam diferenças significativas, a 5\% de probabilidade, pelo teste de Duncan

2 T: trigo; Ap: aveia-preta; E: ervilhaca; M: milho; S: soja; Ab: aveia-branca.

ns $\mathrm{e}^{* *}$ Não-significativo e significativo a $1 \%$ de probabilidade, respectivamente. 
gem de Brachiaria brizantha resultou em melhor rendimento do que após soja em monocultura.

Os resultados ainda mostraram que não houve diferença na nodulação de soja nas diferentes combinações, após cinco anos de sistema plantio direto (Tabela 3). A nodulação apresentou biomassa elevada, superando a considerada suficiente para a fixação biológica de $\mathrm{N}$, desde que os nódulos sejam formados por estirpes eficientes de Bradyrhizobium sp. Desse modo, o efeito benéfico do sistema plantio direto na nodulação de soja, encontrado por Voss \& Sidiras (1985), no Paraná, foi observado no presente experimento, com seqüências de espécies de invernos e no sistema de integração da lavoura com a pecuária.

Os resultados indicaram que a soja pode ser cultivada, sem prejuízos no rendimento de grãos, após aveia-branca, aveia-preta pastejada, aveia-preta + ervilhaca pastejada e trigo, nos diferentes sistemas agrícolas recomendados para a Região Sul do Brasil (Reunião..., 1995).

\section{CONCLUSÃO}

A soja cultivada após aveia-branca, aveia-preta pastejada, aveia-preta + ervilhaca pastejada e trigo pode ser incluída, sem prejuízo, nos diferentes sistemas de sucessão de culturas recomendados para a Região Sul do Brasil.

\section{REFERÊNCIAS}

BARKER, M.R.; WÜNSCHE, W.A. Plantio direto no Rio Grande do Sul. Outlook Agriculture, Oxford, v.9, n.8, p.114-120, 1977.

BRASIL. Ministério da Agricultura. Departamento Nacional de Pesquisa Agropecuária. Divisão de Pesquisa Pedológica. Levantamento de reconhecimento dos solos do Estado do Rio Grande do Sul. Recife, 1973. 431p. (Boletim técnico, 30).

BROCH, D.L.; PITOL, C.; BORGES, E.P. Integração agricultura-pecuária: plantio direto da soja sobre pastagem na integração agropecuária. Maracaju : Fundação MS para Pesquisa e Difusão de Tecnologias Agropecuárias, 1997. 24p. (Fundação MS: Informativo técnico, 1).
COSTAMILAN, L.M.; LHAMBY, J.C.B. Incidência de podridão parda da haste da soja em diferentes sistemas de rotação de culturas. In: REUNIÃO DE PESQUISA DE SOJA DA REGIÃO SUL, 22., 1994, Cruz Alta. Soja: resultados de pesquisa 1993/1994. Passo Fundo : Embrapa-CNPT, 1994. p.63-65.

GAUDÊNCIO, C.A.; YORINORI, J.T.; GARCIA, A.; QUEIROZ, E.F. Rotação de culturas com a soja no norte do Estado do Paraná. Londrina : Embrapa-CNPSo, 1986. 10p. (Embrapa-CNPSo. Pesquisa em Andamento, 10).

MUZILLI, O. Influência do sistema plantio direto, comparado ao convencional, sobre a fertilidade da camada arável do solo. Revista Brasileira de Ciência do Solo, Campinas, v.7, n.1, p.95-102, 1983.

REIS, E.M.; SANTOS, H.P. dos; LHAMBY, J.C.B. Rotação de culturas. I. Efeitos sobre doenças radiculares do trigo nos anos 1981 e 1982. Fitopatologia Brasileira, Brasília, v.8, n.3, p.431-437, 1983.

REUNIÃO DE PESQUISA DE SOJA DA REGIÃO SUL, 21., 1993, Santa Rosa. Recomendações técnicas para a cultura da soja no Rio Grande do Sul e Santa Catarina - safra 1993/94. Santa Rosa : CIENTEC-IPAGRO, 1993. 64p.

REUNIÃO DE PESQUISA DE SOJA DA REGIÃO SUL, 23., 1995, Porto Alegre. Recomendações técnicas para a cultura da soja no Rio Grande do Sul e Santa Catarina 1995/96. Porto Alegre : UFRGS, 1995. 80p.

RUEDELL, J. Plantio direto na região de Cruz Alta. Cruz Alta : FUNDACEP FECOTRIGO, 1995. 134p.

SANTOS, H.P. dos; LHAMBY, J.C.B.; SANDINI, I. Efeitos de sucessões de culturas em plantio direto sobre a soja cultivada em sistemas de rotação de culturas, durante dez anos, em Guarapuava, PR. In: REUNIÃO DE PESQUISA DE SOJA DA REGIÃO SUL, 22., 1994, Cruz Alta. Soja: resultados de pesquisa 1993/1994. Passo Fundo : Embrapa-CNPT, 1994a. p.113-118.

SANTOS, H.P. dos; PEREIRA, L.R.; REIS, E.M. Rotação de culturas em Guarapuava. XIII. Efeitos de sistemas de sucessão de culturas sobre o rendimento de grãos e sobre outras características agronômicas de soja, em plantio direto. Pesquisa Agropecuária Brasileira, Brasília, v.29, n.6, p.907-916, jun. 1994b. 
SANTOS, H.P. dos; PEREIRA, L.R.; REIS, E.M. Rotação de culturas. XXIII. Efeitos das culturas de inverno sobre o rendimento de grãos e sobre algumas características agronômicas de plantas de soja, num período de nove anos. In: REUNIÃO DE PESQUISA DE SOJA DA REGIÃO SUL, 17., 1989, Porto Alegre. Soja: resultados de pesquisa 1988-1989. Passo Fundo : Embrapa-CNPT, 1989a. p.88-99.

SANTOS, H.P. dos; PEREIRA, L.R.; REIS, E.M. Rotação de culturas. XXIV. Efeitos das culturas de inverno sobre o rendimento de grãos e sobre algumas características agronômicas de plantas de soja, num período de cinco anos. In: REUNIÃO DE PESQUISA DE SOJA DA REGIÃO SUL, 17., 1989, Porto Alegre. Soja: resultados de pesquisa 1988-1989. Passo Fundo : Embrapa-CNPT, 1989b. p.100-115.

SANTOS, H.P. dos; REIS, E.M. Efeitos de culturas de inverno sobre o rendimento de grãos e sobre a estatura de plantas da soja. Pesquisa Agropecuária Brasileira, Brasília, v.26, n.5, p.729-735, maio 1991.

SANTOS, H.P. dos; REIS, E.M.; DERPSCH, R. Rotação de culturas. In: EMBRAPA. Centro Nacional de Pesquisa de Trigo (Passo Fundo, RS). Plantio direto no Brasil. Passo Fundo: Embrapa-CNPT /
FUNDACEP FECOTRIGO / Fundação ABC, 1993. p.85-103.

SANTOS, H.P. dos; WOBETO, C. Efeitos de culturas de inverno sob plantio direto sobre a soja cultivada em sistemas de rotação de culturas para trigo, durante dez anos, em Guarapuava, PR. In: REUNIÃO DE PESQUISA DE SOJA DA REGIÃO SUL, 22., 1994, Cruz Alta. Soja: resultados de pesquisa 1993/1994. Passo Fundo : Embrapa-CNPT, 1994. p.107-112.

SOCIEDADE BRASILEIRA DE CIÊNCIA DO SOLO. Comissão de Fertilidade do Solo - RS/SC. Recomendações de adubação e de calagem para os estados do Rio Grande do Sul e Santa Catarina. 3.ed. Passo Fundo, 1995. 223p.

TEDESCO, M.J.; VOLKWEISS, S.J.; BOHNEN, H. Análise de solos, plantas e outros materiais. Porto Alegre : UFRGS, 1985. 32p. (UFRGS-FAGRON. Boletim técnico, 5).

VOSS, M.; SIDIRAS, N. Nodulação da soja em plantio direto em comparação com plantio convencional. Pesquisa Agropecuária Brasileira, Brasília, v.20, n.7, p.775-782, jul. 1985. 